\title{
Spatial-Temporal Dinamics \\ of Siberian Silkmoth Outbreak \\ in Dark Needle Coniferous Forest \\ in Altay Mountains
}

\author{
Elena V. Fedotova ${ }^{* a, b}$ and Anastasiya I. Zarechneva ${ }^{b}$ \\ ${ }^{a}$ V.N. Sukachev Institute of Forest SB RAS \\ 50/28 Akademgorodok, Krasnoyarsk, 660036, Russia \\ ${ }^{b}$ Siberian Federal University \\ 79 Svobodny, Krasnoyarsk, 660041, Russia
}

Received 24.01.2017, received in revised form 10.02.2017, accepted 16.05.2017

The aim of the work is to analyze the possibilities of remote sensing data of medium and high spatial resolution to study the dynamics of fir stands damage by Siberian silkmoth in the Republic of Altai. The outbreak of Siberian silkmoth occurred in 2010-2014. Landsat and Resurs-P Geoton multispectral images were used. Estimations of the damaged forests area and its landscape parameters were made, using the ASTER digital elevation model. The first significant damage and mortality of dark coniferous forests occurred on the slopes of the southwestern exposures, then in the following years, the death of stands spread to the lower and upper portions of the slopes and at least partially warmed the eastern slopes. The area of dead stands is about 6 th. ha. Spectral characteristics of healthy and damaged forest stands on Landsat images most significantly differ in the mid-IR range of 2.11-2.29 microns for Landsat8 OLI (channel 6) or 2.08-2.35 microns for Landsat7 ETM + (channel 7). Interpretation of high spatial resolution Resurs-P Geoton data allows to allocate the area of partial stands damage. Estimated area of partial damaged forests - about 8 th. ha. The most informative is the near-infrared range.

Keywords: Landsat, Resurs-P, Geoton, damage of forests by Siberian silkmoth, spatio-temporal dynamics of the outbreak.

Citation: Fedotova E.V., Zarechneva A.I. Spatial-temporal dinamics of siberian silkmoth outbreak in dark needle coniferous forest in Altay mountains, J. Sib. Fed. Univ. Eng. technol., 2017, 10(6), 747-757. DOI: 10.17516/1999-494X-2017-10-6-747757.

(C) Siberian Federal University. All rights reserved

* Corresponding author E-mail address: elfed@ksc.krasn.ru 


\title{
Пространственно-временная динамика вспышки
}

\author{
массового размножения сибирского шелкопряда \\ в темнохвойных древостоях Горного Алтая
}

\author{
Е.В. Федотова ${ }^{\mathbf{a}, \boldsymbol{\sigma}}$, А.И. Заречнева ${ }^{\boldsymbol{\sigma}}$ \\ ${ }^{a}$ Институт леса им. В.Н. Сукачева СО РАН \\ обособленное подразделение ФИЦ КНЦ СО РАН \\ Россия, 660036, Красноярск, Академгородок, 50/28 \\ ${ }^{6}$ Сибирский федеральный университет \\ Россия, 660041, Красноярск, пр. Свободньй, 79
}

Целью работы является анализ возможностей применения данных дистанционного зондирования среднего и высокого пространственного разрешения в изучении динамики повреждения пихтовых древостоев сибирским иелкопрядом на территории Республики Алтай. Вспьика массового размножения сибирского шелкопряда произошла в 2010-2014 22. В работе использованы многоспектральные изображения Landsat и Ресурс-П. Проведень оченки площуади поврежденных лесов и ландшафтной приуроченности повреждений с применением цицфровой модели рельефа ASTER. Первые значительные повреждения и гибель темнохвойных лесов произошли на склонах юго-западных экспозиций, затем в последующие годы гибель древостоев распространилась на нижние и верхние участки склонов и частично на менее прогреваемые склоны восточной экспозиции. Площцадь погибших древостоев составила 6 тыс. га. Спектральные характеристики здоровых и поврежденных древостоев на снимках Landsat наиболее значительно различаются в среднем ИК диапазоне 2.11-2.29 мкм для Landsat8 OLI (6 канал) или 2.08-2.35 мкм для Landsat7 ETM + (7 канал). Применение данньх высокого пространственного разрешения Ресурс-П Геотон позволяет путём дешифрирования выделить территории частичного повреждения древостоев. Оиенена площадь частичного повреждения лесов - около 8 тыс. га. Наиболее информативен ближний ИК-диапазон.

Ключевые слова: Landsat, Ресурс-П, Геотон, повреждения лесов сибирским шелкопрядом, пространственно-временная динамика вспьики.

\section{Введение}

В формировании современного облика тайги сибирскому шелкопряду принадлежит одна из ключевых ролей. Это насекомое в Сибири является одним из наиболее опасных вредителей хвойных лесов. Периодические подъёмы его численности на значительных площадях приводят к существенным изменениям структуры бореальных лесов, усыханию древостоев и более частым пожарам на этих территориях. Проблема сибирского шелкопряда имеет экономическое, экологическое и социальное значение. С 1878 по 1998 г. в лесах Красноярского края действовали очаги девяти крупномасштабных вспышек массового размножения сибирского шелкопряда на площади свыше 8 млн. га [1]. Насекомое повреждает древостои пихты, сосны, ели и лиственницы. Вспышки массового размножения сибирского шелкопряда индуцируются сочетанием благоприятных погодных условий (оптимальная температура, низкий уровень осадков и влажности). В XXI в. вспышки менее масштабны, но также периодически повторяются в горах Западного Саяна, Алтая [2-5], а в Приенисейской тайге вспышка сибирского шелкопряда наблюдается в настоящее время $[6,7]$. Раннее обнаружение очагов массового размножения и сво- 
евременная борьба с вредителем имеют большое значение для управления лесными ресурсами в поврежденных лесах и ликвидации последствий.

Для оценки площадей, поврежденных насекомыми-вредителями лесов, различия степени повреждений, динамики площадей повреждения и восстановления лесного покрова эффективно используются данные дистанционного зондирования.

Космические снимки с момента их появления используются для мониторинга состояния и оценки степени повреждения лесов вредителями. В работе [8] показана возможность применения данных Landsat-MSS с пространственным разрешением 80 м для обнаружения вспышки массового размножения непарного шелкопряда (Lymantria dispar dispar) в Пенсильвании, США. В [9] временные серии вегетационных индексов использовались для обнаружения повреждений еловых лесов короедом; лучший результат дает разность отношений данных в среднем ИК-диапазоне к значениям в красном диапазоне до и после повреждения. Анализируя снимки Landsat-TM, используя метод линейной смеси в субпиксельной классификации, в [10] показали высокую корреляцию между фракциями темнохвойных лесов в пикселе и уровнем повреждения деревьев короедом.

Данные низкого пространственного разрешения (NOAA/AVHRR, Spot Vegetation, MODIS) позволяют получать временную последовательность параметров, описывающих состояние лесного покрова территории, включая вегетационный индекс нормированной разности (NDVI), с частотой один или несколько раз в сутки, что невозможно для данных Landsat. Анализ отличий временных рядов NDVI и EVI (улучшенный вегетационный индекс) здоровых и поврежденных древостоев используется для оценки площади повреждения и степени повреждения древостоев $[3,11-17]$.

Успешно применяются и позволяют получать значимые результаты данные среднего пространственного разрешения (Landsat, 30 м) в задачах обнаружения, картирования и мониторинга вспышек с использованием NDVI и временных серий космоснимков [18]. Работа [14] посвящена применению данных ASTER NDVI для мониторинга дефолиации тамариска. Оптимальное сочетание диапазонов электромагнитного спектра - зеленый канал (0.5250.605 мкм), ближний инфракрасный (0.750-0.900 мкм), средний инфракрасный (1.55-1.75 мкм) и тепловой канал (10.40-12.50 мкм) [4]. Существенным ограничением использования данных Landsat является то, что повторная съёмка одной территории возможна один раз в 16 дней при отсутствии облачного покрова над исследуемой территорией. Такое ограничение по частоте наблюдения не дает возможность анализировать быстро развивающиеся процессы в экосистемах. Пространственное разрешение порядка 30 м в большинстве перечисленных работ является недостаточным, поэтому чаще всего обращаются к методам субпиксельной классификации снимков, чтобы определить фракции здоровых и поврежденных деревьев в одном элементе разрешения.

Дальнейшее развитие методов анализа повреждения лесов связано с использованием гиперспектральных данных. Их потенциал не полностью исчерпан; применение специальных индексов для узких каналов, метод опорных векторов позволяют улучшить точность выделения повреждений [19]. Генетический анализ (GA) показал, что большой вклад в возможность разделимости классов повреждений между собой и поврежденных древостоев от здоровых вносит зеленый пик (около 0.56 мкм), линии поглощения хлорофиллом (0.68 мкм) и подъёма в области 
границы красного диапазона (red-edge rise (0.69 мкм)). Эти спектральные диапазоны связаны с состоянием стресса растительности. Также линия 1.069 мкм имеет большой потенциал для оценки степени повреждения растительности. Диапазон 1.532 мкм информативен для оценки содержания воды в растениях. Эти результаты согласуются с оценками информативности каналов в мультиспектральной съёмке.

Появившиеся в последние десятилетия данные высокого пространственного разрешения (около 1 м) также успешно используются в анализе состояния и повреждения лесов. Например, для прогнозирования вспышек насекомых-вредителей в эвкалиптовых плантациях в Южной Африке применялись данные WorldView-2 и климатические данные [20]. Наиболее эффективным оказалось применение данных красного и ближнего ИК-каналов и температуры воздуха. Пространственное разрешение уже не требует субпиксельных методов, используются объектно-ориентированные методы классификации, учитывающие не только спектральные характеристики, но и особенности формы крон деревьев.

Наиболее трудная задача - выделение территорий с частично пострадавшими древостоями. Исследования, представленные в работе [21], в которой поврежденные леса выделялись с помощью разновременных снимков Landsat и SPOT и ссылочных данных по аэрофотоснимкам [21], показывают, что достаточно большие участки поврежденных лесов выявляются хорошо, а повреждения текущего, прошлого годов, двухгодичной давности различаются хуже. Однако качество проверочных данных, площадь территорий повреждения, пространственное разрешение данных ДЗ служат решающим фактором для обнаружения более мелких участков.

Цель представленной работы - провести анализ возможностей данных дистанционного зондирования приборов Landsat и Ресурс-П Геотон в задаче оценки динамики площади поврежденных сибирским шелкопрядом лесов и оценить информативность данных разных спектральных каналов для выделения повреждённых лесов. Рассматриваемая в данной работе вспышка прошла на территории Горного Алтая (рис. 1), в пихтовых насаждения Турочакского лесничества с 2009 (начало вспышки, отмеченное при наземных обследованиях) по 2015 г. [22].

\section{Исходные данные и методика работы}

В работе использовались снимки Landsat5, 7, 8 (табл. 1, 2), полученные с геопортала http://earthexplorer.usgs.gov/ в формате GeoTIFF. Пространственное разрешение данных - 30 м, радиометрическое разрешение 8 бит в приборах TM, ETM+ и 12 бит в приборе OLI.

Снимок Ресурс-П Геотон имеет следующие характеристики: радиометрическое разрешение 10 бит/пиксел; четыре спектральных канала (синий 0.45-0.52 мкм, зеленый 0.52-0.6 мкм, красный 0.61-0.68 мкм, ближний ИК 0.72-0.8 мкм); пространственное разрешение 2.07 м [23]. Снимок получен 1 сентября 2014 г.

\section{Предварительная обработка снимков Landsat}

Для упрощения анализа лесных территорий на первом этапе была сделана маска темнохвойных лесов. Она была построена летнему снимку 2006 г. и по зимнему снимку 2010 г. Исключенные нелесные территории имеют небольшую площадь и сосредоточены в основном по 


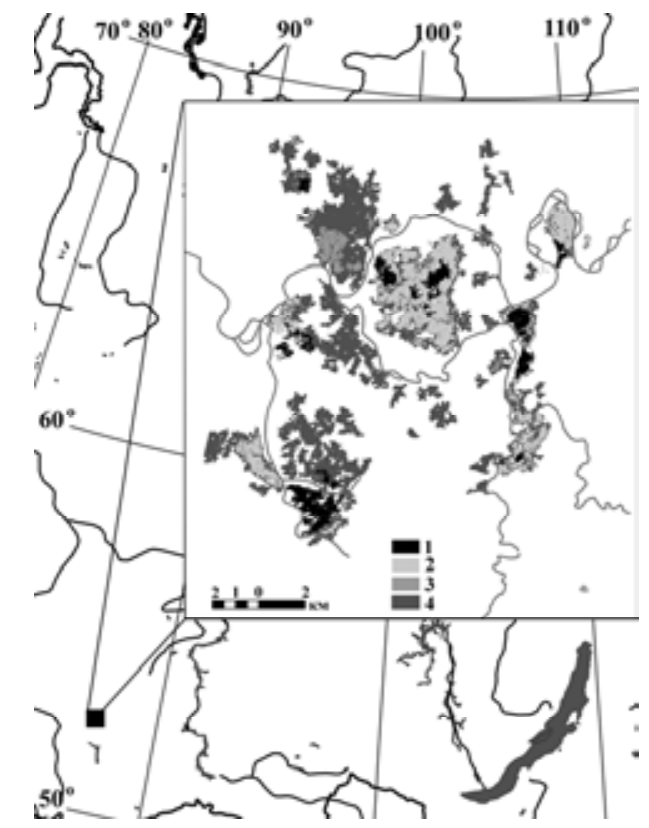

Рис. 1. Район исследования. Во врезке - картосхема поврежденных лесов: 1 - 2010 г., 2 - 2011 г., 3 - 2013 г., $4-2014$ г.

Fig. 1. The area of study. In the box - map of forest damages: $1-2010,2-2011,3-2013,4-2014$

Таблица 1. Снимки, использовавшиеся в работе

Table 1. Images used in the work

\begin{tabular}{|l|l|l|}
\hline \multicolumn{1}{|c|}{ Снимок } & \multicolumn{1}{c|}{ Дата съёмки } & \multicolumn{1}{c|}{ Примечание } \\
\hline LT51450242006171IKR00 & 20 июня 2006 г. & состояние лесов до вспышки \\
\hline LT51450242010022KHC00 & 22 января 2010 г. & исп. для маски т/хв. насаждений \\
\hline LT51450242010230KHC00 & 20 августа 2010 г. & повреждения 2010 г. \\
\hline LT51450242011249IKR01 & 6 сентября 2011 г. & повреждения 2011 г. \\
\hline LE71450242012180PFS00 & 29 июня 2012 г. & повреждения 2012 г. \\
\hline LC81450242013222LGN00 & 10 августа 2013 г. & повреждения 2013 г. \\
\hline LC81450242014193LGN00 & 12 июля 2014 г. & повреждения 2014 г. \\
\hline
\end{tabular}

берегам рек. Для каждого снимка (табл. 1) было собрано многоспектральное изображение с шестью слоями в видимой, ближней и средней инфракрасной (ИК) областях спектра. Был выделен фрагмент снимка, охватывающий территорию поврежденных древостоев (рис. 1), ограниченный координатами $52^{\circ} 27^{\prime}$ с.ш. $/ 87^{\circ} 09^{\prime}$ в.д. и $51^{\circ} 59^{\prime}$ с.ш. $/ 87^{\circ} 55^{\prime}$ в.д.

Были исключены территории, находящиеся на высоте более 650 м над у.м., поскольку при визуальном анализе изображений выше 650 м над у.м. поврежденных лесов нет. Для этой операции, а также для выполнения топографической нормализации снимков методом с-коррекции [24] и анализа приуроченности поврежденных древостоев использовалась цифровая модель рельефа ASTER (ASTER Digital Elevation Model - AST14DEM-Relative, http://asterweb.jpl.nasa. gov/content/03_data/01_Data_Products/release_DEM_relative.htm).

$$
-751-
$$


Таблица 2. Характеристика приборов Landsat5 TM, Landsat7 ETM+, Landsat8 OLI Table 2. Characteristics of the devices Landsat 5 TM, Landsat7 ETM+, Landsat8 OLI

\begin{tabular}{|l|c|c|}
\hline \multirow{2}{*}{ Спектральный канал } & \multicolumn{2}{c|}{ Длина волны, мкм } \\
\cline { 2 - 3 } & TM, ETM+ & OLI \\
\hline Побережья и аэрозоли (Coastal aerosol) & - & $0.43-0.45$ \\
\hline Синий (blue) & $0.45-0.52$ & $0.45-0.51$ \\
\hline Зеленый (green) & $0.53-0.60$ & $0.64-0.67$ \\
\hline Красный (red) & $0.60-0.69$ & $0.85-0.88$ \\
\hline Ближний ИК (near infrared) & $0.77-0.9$ & $1.57-1.65$ \\
\hline Коротковолновой ИК (shortwave infrared); средний ИК & $1.55-1.75$ & $2.11-2.29$ \\
\hline Отражающий ИК (reflective infrared); средний ИК & $2.08-2.35$ & $1.36-1.38$ \\
\hline Перистые облака (Cirrus) & - & \\
\hline
\end{tabular}

\section{Классификаиия снимков}

Задачей классификации являлось разделить здоровый и поврежденный лес. Обучающие выборки поврежденных лесов были построены по материалам наземных исследований 2013 г. на снимке 2013 г. Набор обучающих выборок использовался для классификации снимков 2013 и 2014 гг.

Для снимков 2010, 2011, 2012 гг. обучающие выборки были определены с помощью визуального сравнения изображений и спектральных характеристик здоровых и поврежденных насаждений.

Была проведена классификация тремя методами: максимального правдоподобия, расстояния Махаланобиса и минимального расстояния. Оценка точности классификации проводилась для класса «поврежденные насаждения» по снимку 2014 г. Были выбраны 166 точек методом случайной стратификации. Матрица ошибок представлена в табл. 3. Наиболее точные результаты показал метод максимального правдоподобия. Общая точность классификации составила 87 \%. Каппа-статистика имеет значение 0.86 в целом и 0.79 для класса поврежденных лесов, что соответствует очень хорошему совпадению.

Оценка разделимости обучающих выборок здоровых и поврежденных древостоев с помощью расстояния Джеффриса-Матусита при условии выбора одного или двух признаков (спектральных каналов) показала, что поврежденные леса отделяются от здоровых лучше в среднем ИК-диапазоне - данных шестого и седьмого каналов Landsat OLI или пятого и седьмого каналов приборов ТМ и ЕТМ+.

\section{Классификация снимка Ресурс-П}

Основной задачей, как и с данными Landsat, было разделение здорового и поврежденного леса. Маска темнохвойных лесов не применялась к этому снимку, также как и удаление из рассмотрения территории выше 650 м над у.м., потому что у маски и рельефа гораздо ниже пространственное разрешение: один пиксель Landsat содержит 225 пикселей Геотон. Объектами на снимках Геотон являются кроны деревьев, кустарников, фрагменты напочвенного покрова между деревьями, тени дерева. При классификации снимка было необходимо выделить все классы подстилающей поверхности (здоровые и поврежденные деревья, реки, болота, горы, 
Таблица 3. Матрица ошибок классификации снимка 2014 г.

Table 3. The error matrix of the classification snapshot, 2014

\begin{tabular}{|c|c|c|c|c|}
\hline \multirow{2}{*}{\multicolumn{2}{|c|}{}} & \multicolumn{2}{|c|}{ Классы по ссылочным данным } & \multirow{2}{*}{ Итого } \\
\cline { 2 - 4 } & фон & поврежденный лес & \\
\hline \multirow{2}{*}{$\begin{array}{c}\text { Классы по } \\
\text { классификации }\end{array}$} & фон & 73 & 16 & 89 \\
\cline { 2 - 4 } & поврежденный лес & 1 & 76 & 77 \\
\hline \multicolumn{2}{|c|}{ Количество ссылочных пикселей } & 74 & 92 & 166 \\
\hline
\end{tabular}

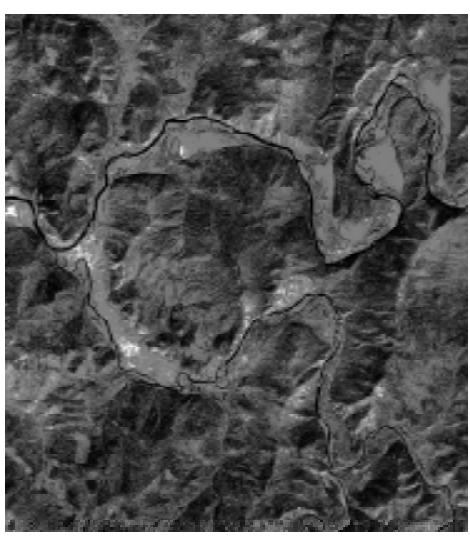

A

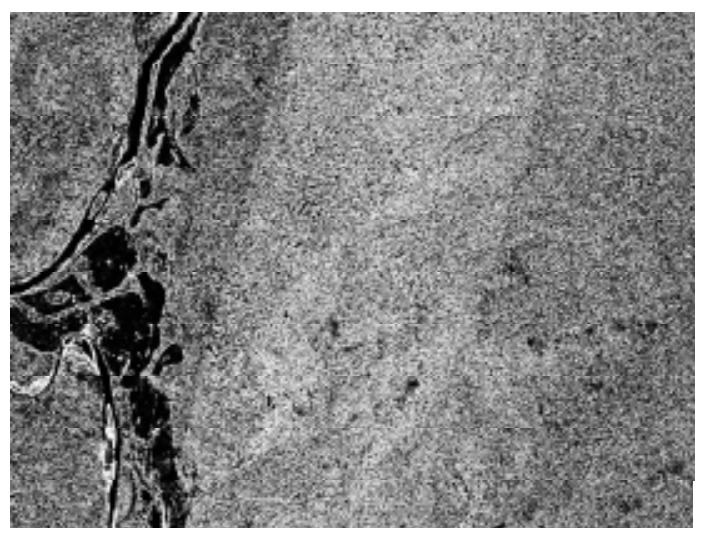

Б

Рис. 2. Данные Ресурс-П Геотон: А - изображение ближнего ИК-канала; Б - текстурный признак дисперсия, третий канал, окно $7 \times 7$

Fig. 2. Data Resource-P Geoton: A - image in the near IR-channel; 5 - the textural characteristic of the dispersion, the third channel, the window is $7 \times 7$

луга), и обучающие выборки строились по отдельным кронам здорового или поврежденного дерева.

Классификация проведена методом максимального правдоподобия. Результат оказался неудовлетворительным - присутствие полос, связанных с качеством исходных данных, не позволило добиваться хорошего качества. Визуально на исходном снимке полосы не просматриваются в каждом из четырех каналов (рис. $2 A$ ). Были рассчитаны текстурные признаки снимка: дисперсия, асимметрия, эксцесс и среднее эвклидово расстояние с разными размерами окна. Текстурный признак дисперсия показал наличие неоднородностей в виде полос в данных третьего канала (видимый красный диапазон) (рис. 2Б).

Поэтому для снимка Геотон было проведено дешифрирование с целью выделения территории частично поврежденных древостоев (рис. 3), которые не были определены при анализе снимков Landsat. Поврежденные деревья отличаются от здоровых особенно сильно в ближнем ИК-канале.

\section{Результаты и обсуждение}

На рис. 4 приведены графики изменения высоты над у.м., крутизны склонов и экспозиции для поврежденных лесов. Нормирование выполнено по отношению к рельефу, не превышающему 650 м над у.м. 


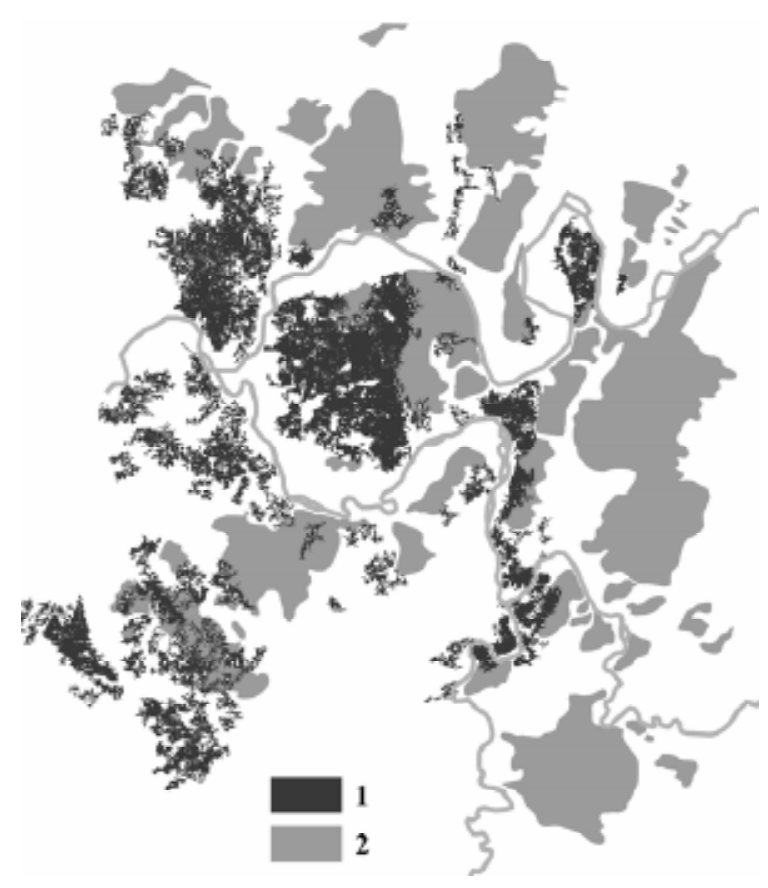

Рис. 3. Погибшие древостои, выделенные по данным Landsat (1), и поврежденные древостои, выделенные по снимку Ресурс-П Геотон (2)

Fig. 3. Dead trees, selected according to the Landsat (1), and damaged forest stands allocated for the snapshot Resource-P Geoton (2)
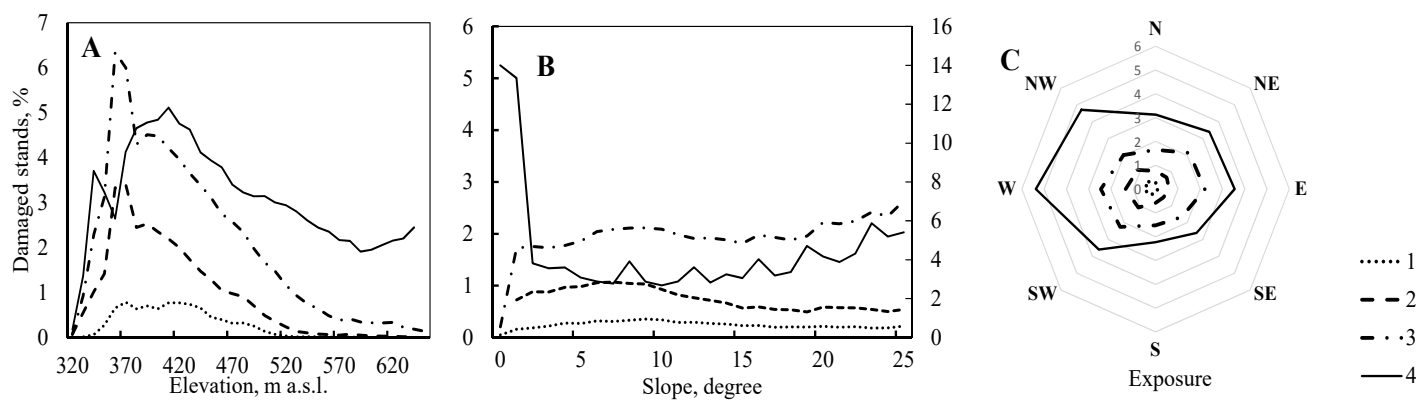

Рис. 4. Нормированные площади высоты над у.м. (А), крутизны (В) и экспозиций склонов (С) территории поврежденных лесов; 1 - 2010 г., 2 - 2011 г., 3 - 2014 г., 4 - по снимку Ресурс-П

Fig. 4. The normalized square of the altitude above sea level (A), slope (B) and aspect of slopes (C) area of damaged forests; 1 - 2010, 2 - 2011, 3 - 2014, 4 - snapshot Resurs-P

Поврежденные в 2010 г. леса занимают площадь около 700 га. В 2011 г. повреждения значительно распространились, и площадь их превысила 2100 га. Очаг распространился на участки с крутизной менее 5 и более 20 градусов, занимая склоны западной экспозиции. В течение 20122013 г. значительного увеличения площади не произошло. Летом 2014 г. (снимок 2014 г. был получен 13 июля) площадь повреждений снова резко увеличилась до 5500 га, повреждения распространились на более крутые склоны, в том числе восточной экспозиции. На рис. 4 показана динамика площади поврежденных древостоев в 2010-2014 гг. 
На снимке Ресурс-П Геотон поврежденные деревья хорошо выделяются по данным в четвертом канале - ближнем ИК-диапазоне. Визуальное дешифрирование снимка позволило выделить участки частично поврежденных древостоев, где сохранились здоровые деревья, либо поврежденный шелкопрядом древостой разрежен, что пропускается при классификации снимков Landsat. Площадь частично поврежденных древостоев составила около 8 тыс. га. Распостраниние произошло вверх по высоте склонов, захвачены также пологие участки долин, более выражена ориентация на западных склонах.

\section{Заключение}

Серия многоспектральных снимков Landsat с 2010 по 2014 г. позволила провести анализ распространения площади поврежденных сибирским шелкопрядом темнохвойных лесов. Спектральные характеристики здоровых и поврежденных древостоев наиболее значительно различаются в среднем ИК-канале: 2.11-2.29 мкм для L8 (2.08-2.35 мкм для L7). Это показывает, что уменьшается влажность отражающей поверхности - более влажная хвоя исчезает, заменяется более сухими стволами, ветвями, напочвенным покровом, достаточно бедным в пихтовых лесах. Различия отражательной способности в ближней ИК-области оказываются меньше. На снимке Ресурс-П Геотон поврежденные деревья хорошо выделяются по данным в четвертом канале - ближнем инфракрасном диапазоне. В результате классификация и дешифрирования данных Landsat и Ресурс-П Геотон была оценена ландшафтная приуроченность и площадь поврежденных древостоев, которая составила суммарно около 14 тыс. га.

Работа выполнена при поддержке гранта Российского научного фонда № 14-24-00112.

\section{Список литературы}

[1] Кондаков Ю.А. Массовые размножения сибирского шелкопряда в лесах Красноярского края. Энтомологические исследования в Сибири, 2002, вып. 2, Красноярск, КФ РЭО, 25-74. [Kondakov Y.A. Siberian silkmoth outbreaks in Krasnoyarsk region forests, Entomological researches in Siberia, 2002, 2, Krasnoyarsk, 25-74 (in Russian)]

[2] Kharuk V.I., Ranson K.J., Fedotova E.V. Spatial pattern of Siberian silkmoth outbreak and taiga mortality. Scandinavian Journal of Forest Research, 2007, 22, 531-536.

[3] Kharuk V.I., Ranson K.J., Im S.T. Siberian silkmoth outbreak pattern analysis based on SPOT VEGETATION data. International Journal of Remote Sensing, 2009, 30, 9, 2377-2388.

[4] Kharuk, V.I., Ranson, K.J., Kuz'michev, V.V. and Im, S.T., Landsat-based analysis of insect outbreaks in southern Siberia. Canadian Journal of Remote Sensing, 2003, 29(2), 286-297.

[5] Kharuk V.I., Demidko D.A., Fedotova E.V., Dvinskaya M.L., Budnik U.A. Spatial and temporal dynamics of Siberian silk moth large-scale outbreak in dark-coniferous tree stands in Altai. Contemporary problems of ecology, 2016, 9, 6, 718-727.

[6] Леса Красноярского края пытаются спасти от сибирского шелкопряда. Информационное агентство REGNUM, 7 ноября 2016 г.; https://regnum.ru/news/society/2202018.html [Krasnoyarsk region forests are trying to protect from Siberian silkmoth outbreak. Informational agency REGNUM, 7 November 2016; https://regnum.ru/news/society/2202018.html (in Russian)] 
[7] Первый лесопромышленный портал. «В 2016 году в лесах Сибирского федерального округа была зафиксирована вспышка размножения сибирского шелкопряда», 13 декабря 2016 г.; http://www.wood.ru/ru/lonewsid-72740.html [First forestry portal. «In 2016 in the Siberian federal region the Siberian silkmoth outbreak was detected», 13 December 2106; http://www.wood.ru/ $\mathrm{ru} /$ lonewsid-72740.html (in Russian)]

[8] Dottavio C.L. Williams D.L. Satellite technology and improved means for monitoring forest insect defoliation. J. Forestry, 1983, 81, 1, 30-34.

[9] Nelson R.F. Detecting forest canopy change due to insect activity using Landsat MSS. Photogram. Eng. and Rem. Sens., 1983, 49, 1303-1314.

[10] Radeloff V.C. Mladenoff D.J. Boyce M.S. Detecting Jack Pine budworm defoliation using spectral mixture analysis: Separating effects from determinants. Rem. Sens. Environ., 1999, 69, 2, 156-169.

[11] Kharuk V.I., Ranson K.J., Kozuhovskaya A.G., Kondakov Y.P., Pestunov I.A. NOAA/AVHRR satellite detection of Siberian silkmoth outbreaks in eastern Siberia. International Journal of Remote Sensing, 2004, 25:24, 5543-5556, DOI: 10.1080/01431160410001719858.

[12] Beurs K.M. de, Townsend P.A. Estimating the effect of gypsy moth defoliation using MODIS. Remote Sensing of Environment, 112, 2008, 3983-3990.

[13] Eklundh L., Johansson T., Solberg S. Mapping insect defoliation in Scots pine with MODIS time-series data. Remote Sensing of Environment, 113, 2009, 1566-1573.

[14] Dennison P.E., Nagler P.L., Hultine K.R., Glenn E.P., Ehleringer J.R. Remote monitoring of tamarisk defoliation and evapotranspiration following saltcedar leaf beetle attack. Remote Sensing of Environment, 113, 2009, 1462-1472.

[15] Jepsen J.U., Hagen S.B., Høgda K.A., Ims R.A., Karlsen S.R., TømmervikH., Yoccoz N.G. Monitoring the spatio-temporal dynamics of geometrid moth outbreaks in birch forest using MODISNDVI data. Remote Sensing of Environment, 113, 2009, 1939-1947.

[16] Spruce J.P., Sader S., Ryan R.E., Smoot J., Kuper P., Ross K., Prados D., Russell J., Gasser G., McKellip R, Hargrove W. Assessment of MODIS NDVI time series data products for detecting forest defoliation by gypsy moth outbreaks. Remote Sensing of Environment, 115, 2011, 427-437.

[17] Им С.Т., Харук В.И., Федотова Е.В. Спектрорадиометрическая космосъемка в анализе зоны вспышки массового размножения сибирского шелкопряда. Журнал СФУ, серия Техника и технологии, 2008, 1, 4, 346-358 [Im S.T., Kharuk V.I., Fedotova E.V. Spectroradiometrical space sensing in the analisys of Siberian silkmoth outbreak zone, Journal of SFU, Engineering and technologies, 2008, 1, 4, 346-358 (in Russian)]

[18] Royle D.D., Lathrop R.G. Discriminating Tsuga Canadensis hemlock forest defoliation using remotely sensed change detection. Journal of Nematologi, 2002, 34(3), 213-221.

[19] Fassnacht F.E., Latifi H., Ghosh A., Joshi P.K., Koch B. Assessing the potential of hyperspectral imagery to map bark beetle-induced tree mortality. Remote Sensing of Environment, 140, 2014, 533-548.

[20] Oumar Z., Mutanga O. Integrating environmental variables and WorldView-2 image data to improve the prediction and mapping of Thaumastocoris peregrinus (bronze bug) damage in plantation forests. ISPRS Journal of Photogrammetry and Remote Sensing, 87, 2014, 39-46. 
[21] Latifi H., Schumann B., Kautz M., Dech S. Spatial characterization of bark beetle infestations by a multidate synergy of SPOT and Landsat imagery. Environmental monitoring and assessment, 2014, 186, 1, 441-456.

[22] Леса Горного Алтая, М.: Наука, 1965, 224 [Mountain Altay forests, M: Nauka, 1965, 224 (in Russian)]

[23] Кирилин А.Н., Ахметов Р.Н., Стратилатов Н.Р., Бакланов А.И., Федоров В.М., Новиков М.В. Космический аппарат «Ресурс-П». Геоматика, 2010, 4, 23-26 [Kirilin A.N., Achmetov R.N., Stratilatov N.R., Baklanov A.I., Fedorov V.M., Novikov M.V. Space device «Resurs-P». Geomatica, 2010, 4, 23-26 (in Russian)]

[24] Riano D., Chuvieco E., Salas J., Aguado I. Assessment of Different Topographic Corrections in Landsat-TM Data for Mapping Vegetation Types. IEEE Transactions On Geoscience And Remote Sensing, 2003, 41, 5, 1056-1061. 